\title{
Association of first trimester serum level of placental growth factor (PIGF) and cervical length with onset of preterm labour
}

\author{
Ipsita Sahoo', Madhusudan Dey ${ }^{2 *}$, Jayamol A. ${ }^{3}$
}

\author{
${ }^{1}$ Department of Obstetrics and Gynecology, Military Hospital Ambala, Haryana, India \\ ${ }^{2}$ Department of Obstetrics and Gynecology, Army College of Medical Sciences, Delhi, India \\ ${ }^{3}$ Department of Obstetrics and Gynecology, INHS Dhanvantari, Andaman and Nicobar Islands, India
}

Received: 14 February 2019

Accepted: 07 March 2019

\author{
*Correspondence: \\ Dr. Madhusudan Dey, \\ E-mail: deym1@yahoo.com
}

Copyright: (c) the author(s), publisher and licensee Medip Academy. This is an open-access article distributed under the terms of the Creative Commons Attribution Non-Commercial License, which permits unrestricted non-commercial use, distribution, and reproduction in any medium, provided the original work is properly cited.

\begin{abstract}
Background: Preterm labour (PTL) or premature labour is defined as one where labour starts before the 37th completed week. The incidence of preterm birth is around $5-10 \%$ and it is the leading cause of perinatal morbidity and mortality. Diagnosis and treatment of PTL is challenging. However, owing to the availability of effective strategies for prevention of preterm birth, risk identification and early prediction is even more essential. This may provide opportunity for intervention and better obstetric care. Various biochemical markers were studied for prediction of preterm labour, but the sensitivity and specificity were found to be low. This study focuses on determining whether serum level of PIGF and ultrasound measure of cervical length at $10-14$ weeks period of gestation can be used for early prediction of preterm labour.

Methods: 296 antenatal women participated in this prospective observational study carried out from Dec 2015 to Sep 2017 at a tertiary care hospital. Serum level of PlGF was determined at 10-14 weeks. In the same sitting, cervical length was measured by transvaginal sonography. All these patients were followed up in antenatal OPD for monitoring the onset of preterm labour.

Results: Incidence of preterm labour was $6.76 \%$. Maternal characteristics and obstetric factors were comparable in cases and controls. Serum PIGF level and cervical length values were lower in preterm labour group than term deliveries. But this result was not statistically significant.

Conclusions: Lower levels of PIGF and cervical length were seen in preterm labour group, although it was not found to be statistically significant.
\end{abstract}

Keywords: Cervical length, Perinatal mortality, Preterm labour, Placental growth factor (PlGF), Ultrasound

\section{INTRODUCTION}

Preterm delivery (PTD) defined by World Health Organization as birth before the completion of 37 weeks of gestation, is the leading cause of perinatal mortality and long-term morbidity and the incidence of preterm birth around 5-10\%. ${ }^{1}$ Deliveries between 28 to 34 weeks are called early preterm births. Those between 34 and 36 +6 weeks are called late preterm births. Study by Martin et al showed that late preterm births account for $71.2 \%$ of all preterm births. ${ }^{2}$ Recent studies of the epidemiology and pathophysiology of preterm birth have identified inflammation, decidual haemorrhage, uterine overdistension and premature activation of the normal physiologic initiators of labour to be four major pathways leading to preterm labour and delivery. All these diverse processes culminate in a common end point to cause premature cervical dilatation and effacement and 
activation of uterine contractions. Diagnosis and treatment of preterm labour is challenging, but its early prediction allows for commencement of proven prophylactic therapies, institution of an appropriate model of antenatal care and level of clinical surveillance. ${ }^{3}$

Numerous studies have shown that abnormal concentration of first trimester serum markers is related to the onset of preeclampsia, small for gestational age and preterm delivery. The predictability value of biochemical marker in the first trimester has an important role in use of prophylactic progesterone, administration of antenatal steroids and close antenatal surveillance of patients in improving obstetric outcome in high risk cases. Placental Growth Factor (PIGF) is an angiogenic protein secreted by the placenta, acting in synergy with the Vascular Endothelial Growth Factor (VEGF), PIGF has been shown to be necessary for the proper functioning of the endothelial cells during pregnancy. ${ }^{4}$ Bastek et al showed that in preterm delivery low PIGF levels are associated with high levels of a marker of inflammation, such as the C-Reactive Protein (CRP), suggesting an interplay between inflammation and placental dysfunction in the pathogenesis of preterm labour. ${ }^{5}$ Pregnant women having spontaneous delivery before 34 weeks found to have shorter cervical length during first trimester as compared to those delivering after 34 weeks. Souka et al. measure the cervical length in 800 women with singleton pregnancies and showed that cervical length at 11-14 weeks of gestation predicted preterm delivery before 34 weeks. ${ }^{6}$ The objective of this study was to assess if there is an association between first trimester serum PlGF and cervical length with onset of preterm labour.

\section{METHODS}

This was a prospective observational study carried out at a tertiary care teaching hospital of Pune, India between Dec 2014 to Sep 2016. Local institutional ethical committee approved the study protocol.

\section{Inclusion criteria}

- A total of 296 pregnant women registered during 1014 weeks period of gestation (POG).

\section{Exclusion criteria}

- Patients with uterine anomalies,

- Chronic hypertension,

- Overt diabetes mellitus,

- Multiple gestation,

- History of recurrent urinary tract infection or previous history of preterm delivery.

Informed consent was taken from all women enrolled in the study. Detailed history taking and examination was carried out. Period of gestation (POG) was confirmed by dates and correlated with USG. In case of unsure dates, USG-EDD was taken to calculate POG. $8 \mathrm{hrs}$ fasting blood samples were collected from all patients at 10 $13+6$ weeks POG for measurement of their serum PlGF levels. The PIGF levels were measured by ELISA technique. In the same sitting, cervical length was measured by transvaginal sonography using $7.5 \mathrm{MHz}$ probe. Adequate privacy was maintained during examination. Cases were further followed up in antenatal OPD for monitoring the onset of preterm labour. Data so obtained were statistically analysed by available statistical software.

\section{Statistical analysis}

Statistical analysis was done using SPSS version 20. The 2 independent sample t-test and Mann-Whitney $U$ test were used for data analysis. $\mathrm{P}$ value of less than 0.05 was considered significant.

\section{RESULTS}

In present study, total of 296 antenatal patients between 10-14 weeks of gestation were recruited after meeting the inclusion and exclusion criteria. Serum PlGF level and cervical length was measured for every patient. All patients were followed up till delivery and data on different aspects were collected. During the follow up period, 30 patients lost to follow up. Hence, data of 266 patients was taken for analysis. Out of 266 patients, 18 patients $(6.76 \%)$ developed preterm labour and delivered before 37 completed weeks. 248 patients $(93.24 \%)$ had full term deliveries.

For study analysis, 18 patients who had preterm labour were taken as cases and remaining 248 as controls. Out of the 18 preterm deliveries, there were 8 early preterm births (28-34 weeks) and 10 late preterm births (34+1 $36+6$ weeks).

Maternal characteristics were tabulated in Table 1 and there were no statistically significant difference in both the groups. The obstetric factors were shown in Table 2. There was significant difference in POG at delivery, neonatal birth weight and NICU admission among cases and controls.

Table 1: Maternal characteristics in cases and controls.

\begin{tabular}{|c|c|c|c|}
\hline Characteristic & $\begin{array}{l}\text { Controls } \\
(\mathrm{n}=248)\end{array}$ & $\begin{array}{l}\text { Cases } \\
(n=18)\end{array}$ & P value \\
\hline Age (years) & 23.9 & 23.7 & $>0.05$ \\
\hline BMI $\left(\mathrm{kg} / \mathrm{m}^{2}\right)$ & 20.56 & 20.57 & $>0.05$ \\
\hline $\begin{array}{l}\text { Systolic BP } \\
\text { (mm of Hg) }\end{array}$ & 114.76 & 118.6 & $>0.05$ \\
\hline $\begin{array}{l}\text { Diastolic BP } \\
(\mathrm{mm} \text { of } \mathrm{Hg})\end{array}$ & 72.16 & 74.84 & $>0.05$ \\
\hline $\begin{array}{l}\text { Blood sample taken } \\
\text { at POG (days) }\end{array}$ & 87.8 & 85.9 & $>0.05$ \\
\hline Primipara (Total no.) & 118 & 10 & $>0.05$ \\
\hline Multipara (Total no.) & 130 & 8 & $>0.05$ \\
\hline
\end{tabular}


Table 2: Obstetric factors in cases and controls.

\begin{tabular}{|l|l|l|l|}
\hline Obstetric factors & $\begin{array}{l}\text { Controls } \\
(\mathbf{n = 2 4 8})\end{array}$ & $\begin{array}{l}\text { Cases } \\
(\mathbf{n = 1 8})\end{array}$ & $\begin{array}{l}\mathbf{P} \\
\text { value }\end{array}$ \\
\hline $\begin{array}{l}\text { Delivery at POG } \\
\text { (Days) }\end{array}$ & 270 & 241 & $<0.05$ \\
\hline $\begin{array}{l}\text { Normal delivery } \\
\text { (Total no. })\end{array}$ & $\begin{array}{l}179 \\
(72.2 \%)\end{array}$ & $\begin{array}{l}12 \\
(66.8 \%)\end{array}$ & $>0.05$ \\
\hline $\begin{array}{l}\text { Cesarean delivery } \\
\text { (Total no. })\end{array}$ & $61(27.8 \%)$ & $6(33.2 \%)$ & $>0.05$ \\
\hline $\begin{array}{l}\text { Neonatal birth } \\
\text { weight (Kg) }\end{array}$ & 2.79 & 2.18 & $<0.05$ \\
\hline $\begin{array}{l}\text { NICU admission } \\
\text { (Total no. })\end{array}$ & 3 & 10 & $<0.05$ \\
\hline
\end{tabular}

Serum level of PlGF among cases and controls is shown in Figure 1.

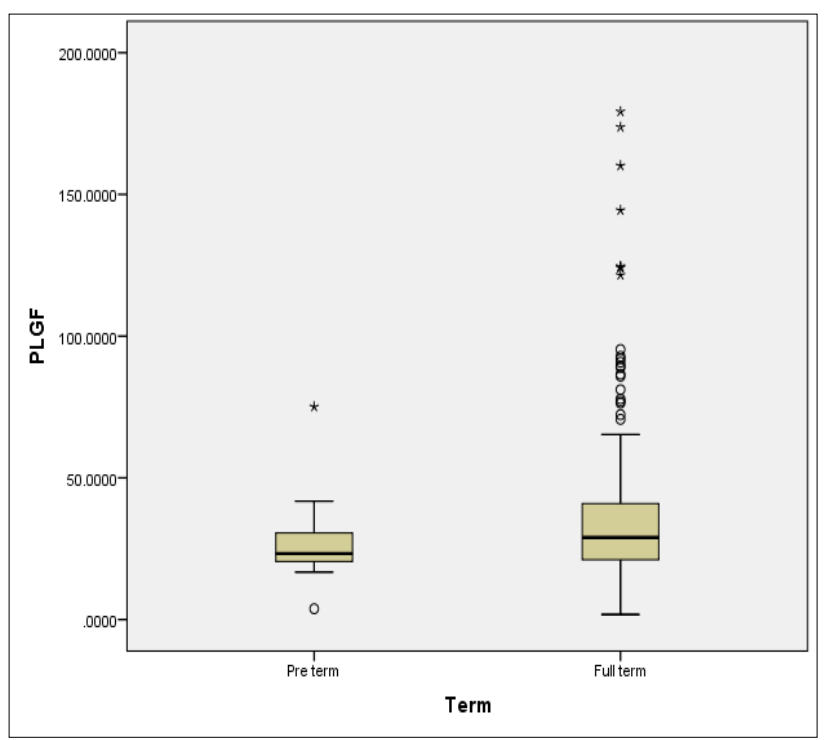

Figure 1: Box and Whisker plot after excluding extremes for PLGF.

In present study, median PlGF value of patients who delivered preterm was $23.3 \mathrm{pg} / \mathrm{ml}$ whereas in those with full term deliveries were $28.93 \mathrm{pg} / \mathrm{ml}$ with a $\mathrm{P}$ value of 0.126 (Table 3). Using the Mann Whitney U test, with $\mathrm{P}$ value $<0.05$, the median PlGF value was not statistically significant between cases and controls.

Table 3: Maternal serum PIGF and cervical length in cases and controls.

\begin{tabular}{|c|c|c|c|}
\hline \multirow[b]{2}{*}{ Parameters } & \multicolumn{2}{|c|}{ Median values } & \multirow[b]{2}{*}{$\begin{array}{l}\mathbf{P} \\
\text { value }\end{array}$} \\
\hline & $\begin{array}{l}\text { Controls } \\
(n=248)\end{array}$ & $\begin{array}{l}\text { Cases } \\
(n=18)\end{array}$ & \\
\hline PLGF (pg/ml) & 28.93 & 23.3 & 0.126 \\
\hline Cervical length $(\mathrm{cm})$ & 3.72 & 3.68 & 0.953 \\
\hline
\end{tabular}

Cervical length by TVS among cases and controls is shown in Figure 2. The median cervical length by TVS among cases was $3.64 \mathrm{~cm}$ and in controls was $3.72 \mathrm{~cm}(\mathrm{P}$ value $=0.953$ ). Using the Mann Whitney $\mathrm{U}$ test, $\mathrm{P}$ value $>0.05$, the result was not statistically significant in present study.

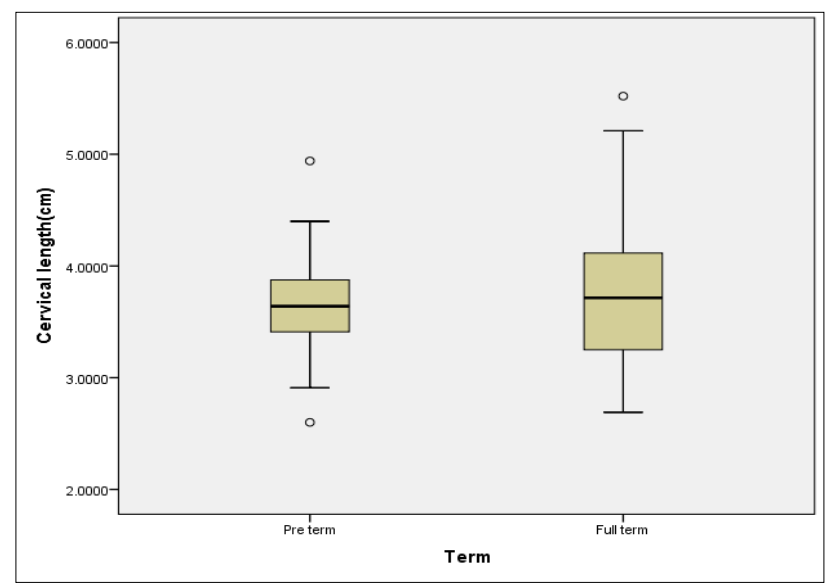

Figure 2: Box and Whisker plot after excluding extremes for cervical length.

\section{DISCUSSION}

Despite significant advances in perinatal medicine and establishment of fetomaternal units, preterm birth still remains the leading cause of perinatal mortality and neonatal morbidity representing one of the principle targets of obstetrical health care. Preterm babies predominantly suffer not only from the immediate complication of prematurity but also long-term neurodevelopmental disability. Hence identification of women at increased risk of PTL is of paramount importance and then prevention is the elusive goal. The therapy with most evidence for preventing PTD has been progesterone replacement therapy.

Also, in singleton pregnancies who had a previous PTD and cervix $<25 \mathrm{~mm}$, a cerclage placed during second trimester will reduce the risk of PTB by $35-40 \%$ before 35 weeks as reported in a meta-analysis. ${ }^{7}$ Tocolytics are used for women in preterm labour to delay delivery upto 48 hours, permit time for corticosteroid therapy and allow transport to higher center if need be. Despite all these interventions, the rate of preterm delivery has not reduced in the past 30 years, mainly because of failure to identify the high-risk group during routine prenatal care. ${ }^{1,8}$ Also, the incidence of preterm birth continues to rise due to increased multiple pregnancies as a result of assisted reproduction. $^{8}$ In present study, out of 266 women studied, 18 of them had PTD.

The incidence of preterm labour in present study was $6.76 \%$ which was corroborates with available literature. ${ }^{1}$ Preterm labour is a quintessentially multifactorial condition. Risk increases when age is $<18$ or $>35$ years. Age profile of present study population was from 19 to 35 years. The mean age of patients who delivered at term and preterm gestation was comparable. It was 23.9 years 
in cases and 23.7 years in controls. Overweight and obese mothers are at elevated risk of PTD. ${ }^{9}$ In present study, most of the women had normal BMI in the range 18.51 to $24.5 \mathrm{~kg} / \mathrm{sqm}$. The mean BMI in cases and controls was also comparable. In present study, 191 patients $(71.8 \%)$ underwent vaginal delivery. 67 patients $(25.1 \%)$ were delivered by Lower segment cesarean section (LSCS). 6 cases $(2.2 \%)$ had successful Vaginal birth after cesarean (VBAC) and 2 patients $(0.75 \%)$ underwent vacuum delivery. 11 patients $(4.13 \%)$ in present study developed preeclampsia and out of these $3(1.1 \%)$ had PTB.

As such, hypertensive disorders of pregnancy have 12-34 $\%$ risk of PTL. The mean POG at delivery in cases was 241 days whereas it was 270 days in the controls and this difference was statistically significant. Similarly, mean neonatal birth weight in cases was $2.21 \mathrm{~kg}$ whereas in controls was $2.8 \mathrm{~kg}$ showing significant difference.

More babies needed NICU admission among cases in view of low birth weight and prematurity. In present study, median PlGF value of cases was $23.3 \mathrm{pg} / \mathrm{ml}$ whereas in controls was $28.93 \mathrm{pg} / \mathrm{ml}$ with a $\mathrm{P}$ value of 0.126 . Using the Mann Whitney $\mathrm{U}$ test, $\mathrm{P}$ value $<0.05$, and this result was not statistically significant. However, the cases had lower PIGF values compared to controls. Thus, PlGF in first trimester cannot be utilised as a screening test for preterm labour as depicted by our results.A similar study was done by Azteni et al. ${ }^{10}$

The PlGF levels were measured in plasma samples collected from 122 pregnant women between 20-35 weeks of pregnancy. In this study, PlGF levels were significantly lower than cut-off values in all women with preterm delivery without known causes.

Bastek et al showed that in preterm delivery low PIGF levels are associated with high levels of a marker of inflammation, such as the $\mathrm{C}$ - reactive protein, suggesting interplay between inflammation and placental dysfunction in the pathogenesis of preterm labour. ${ }^{5}$

In present study, the median cervical length by transvaginal ultrasound in cases was $3.64 \mathrm{~cm}$ and in controls was $3.72 \mathrm{~cm}(\mathrm{P}$ value $=0.953)$. Using the Mann Whitney $U$ test, $P$ value $>0.05$ and there was no statistically significant difference in median cervical length between preterm and term deliveries. However, the cervical length between 10-14 weeks was slightly lesser in cases than controls. Several studies reported that measurement of cervical length in the first trimester is not predictive of preterm delivery. ${ }^{11}$

The role of cervical length measurement at 11-14 weeks of gestation for the prediction of preterm delivery is not well defined yet. But the study conducted by Souka et al, measured the cervical length in 800 women with singleton pregnancies and showed that cervical length at 11-14 weeks of gestation predicted preterm delivery. ${ }^{6}$
The strengths of present study include the prospective design and high follow up rate. In addition, almost all our patients had similar socio-economic status and education. However, the study was not without limitations. It had a small sample size and comprised study of limited number of risk factors. Also, authors cannot exclude the possibility of the other confounding from unmeasured covariates. Finally, another limitation was that it was done in only one medical centre.

\section{CONCLUSION}

In present study, authors conclude that though lower levels of PlGF and cervical length were seen in the preterm labour group, this result was not statistically significant. Hence, no association could be made between the above two parameters and preterm labour. However, it would be prudent to replicate the study in a wider and more representative sample over multiple centres to see if the result holds true.

\section{Funding: No funding sources Conflict of interest: None declared \\ Ethical approval: The study was approved by the Institutional Ethics Committee}

\section{REFERENCES}

1. Goldenberg RL, Culhane JF, Iams JD, Romero R. Epidemiology and causes of preterm birth. The lancet. 2008;371(9606):75-84.

2. Martin JA, Osterman MJ, Centers for Disease Control and Prevention (CDC). Preterm birthsUnited States, 2006 and 2010. MMWR Surveill Summ. 2013;62(suppl 3):136-8.

3. Kane SC, da Silva Costa F, Brennecke S. First trimester biomarkers in the prediction of later pregnancy complications. BioMed Research International. 2014;2014.

4. Krauss T, Pauer HU, Augustin HG. Prospective analysis of placenta growth factor (PlGF) concentrations in the plasma of women with normal pregnancy and pregnancies complicated by preeclampsia. Hypertension in pregnancy. 2004;23(1):101-11.

5. Bastek JA, Brown AG, Anton L, Srinivas SK, D'addio A, Elovitz MA. Biomarkers of inflammation and placental dysfunction are associated with subsequent preterm birth. J Mat-Fet Neonatal Med. 2011;24(4):600-5.

6. Souka AP, Papastefanou I, Michalitsi V, Papadopoulos GK, Kassanos D. A predictive model of short cervix at 20-24 weeks using first-trimester cervical length measurement and maternal history. Prenatal Diagnos. 2011;31(2):202-6.

7. Berghella V, Keeler S, To M, Althuisius S, Rust O. Effectiveness of cerclage according to severity of cervical length shortening: a meta-analysis. Ultrasound Obstet Gynecol. 2010;35(4):468-73. 
8. Allen VM, Wilson RD, Cheung A, Blight C, Désilets VA, Gagnon A, et al. Pregnancy outcomes after assisted reproductive technology. J Obstet Gynaecol Canada. 2006;28(3):220-33.

9. Cnattingius S, Villamor E, Johansson S, Bonamy AKE, Persson M, Wikström A-K, et al. Maternal obesity and risk of preterm delivery. Jama. 2013;309(22):2362-70.

10. Atzeni I, Paoletti AM, Deiana SF, Meloni A, Guerriero S, Parodo G et al. W239 placental growth factor (PLGF): Correlations with placental function. Int J Gynecol Obstet. 2012;119:S782-3.
11. Carvalho MHB, Bitter RE, Brizot MA, Maganha PPS, Zugaib M. Cervical length at 11-14 weeks and 22-24 weeks gestation evaluated by transvaginal sonography, and gestational age at delivery. Ultrasound Obstet Gynaecol.2003;21(2):135-9.

Cite this article as: Sahoo I, Dey M, Jayamol A. Association of first trimester serum level of placental growth factor (PIGF) and cervical length with onset of preterm labour. Int J Reprod Contracept Obstet Gynecol 2019;8:1641-5. 